\title{
In-Depth Chemical Analysis of Particulate Matter Emitted by Agarwood: Study of Environmental Impact
}

\author{
Arif Hussain Kaleri, ${ }^{1,2}$, Hao Fu Dai ${ }^{1,2}$, Xi-Qiang Song ${ }^{1,2 *}$, Anum Mehmood ${ }^{4}$, \\ Saqib Ali Nawaz ${ }^{5}$, Ghulam Sajjad Kaleri ${ }^{3}$, Mir Muhammad Nizamani,2, \\ Aamir Ali Khokhar ${ }^{4}$, Mughair Aslam Bhatti ${ }^{4}$, Abdul Rasheed Kaleri ${ }^{3}$
}

${ }^{1}$ Key Laboratory of Genetics and Germplasm Innovation of Tropical Special Forest Trees and Ornamental Plants (Hainan University), Ministry of Education, College of Forestry, Hainan University, Haikou, P. R. China ${ }^{2}$ Key Laboratory of Germplasm Resources of Tropical Special Ornamental Plants of Hainan Province, College of Forestry, Hainan University, Haikou, P. R. China

${ }^{3}$ Department of Agronomy Sindh Agriculture University Tando Jam, Hyderabad, Sindh, 70060 Pakistan ${ }^{4}$ Hainan University, Haikou China

${ }^{5}$ College of Information and Communication Engineering Hainan University, Haikou, China 5702282

Received: 14 April 2021

Accepted: 25 May 2021

\begin{abstract}
Agarwood is mainly used to make incense, perfume, traditional Chinese medicine, and other products. In some parts of China, some consumers use cigarettes that contain agarwood. Not all Aquilaria trees can generate agarwood; only trees that are damaged by natural and artificial means form resin. Due to the short time of forming resin, there are some differences in the quality of agarwood. This paper studies the effects of the application of cultivated agarwood in incense, cigarettes, and essential oil. First, the differences in combustion as an incense of this cultivated agarwood and three samples of natural agarwood were researched, and the cytotoxic and genotoxic of aerosols of combustion were tested. Subsequently, the effect of the application of this cultivated agarwood in cigarettes was studied. The particulate matter particles of four samples of agarwood incense burning smoke were detected. The ultrafine particles and fine particles accounted for the vast majority (more than 99\%) by number and by mass, and these can enter the human alveoli and have a negative impact on health.
\end{abstract}

Keywords: agarwood, particulate matter, environmental pollution

*e-mail: 2159440738@qq.com 


\section{Introduction}

Aquilaria is a resinous hardwood formed by trees of the genus Aquilaria Lam (Thymelaeaceae). Currently, 19 species are recognized as being capable of producing an aroma, of which four are the most important: Aquilaria malaccensis, Aquilaria crassna, Aquilaria sinensis, and Aquilaria rugosa. The main incense is Aquilaria sinensis (Lour.) Gilg., which is mainly produced in Hainan, Taiwan, Guangdong, and Guangxi. Agarwood trees mostly grow at an altitude of about $1500 \mathrm{~m}$. They are large evergreen trees with a height of up to $30 \mathrm{~m}$ and a diameter of up to $1 \mathrm{~m}$. In addition, Indonesia, Malaysia, Vietnam, Cambodia, Laos, and Papua New Guinea are agarwood-producing areas [1]. Worldwide, the production of agarwood has increased in last 20 years, as shown in Fig. 1.

In recent years, artificial incense technology has developed rapidly, and breakthroughs have been made. The artificial agarwood that has been produced on a large scale will enter the market. Because of the application safety issues, the market access threshold for medicinal materials is relatively high. The application market of agarwood must be concentrated in incense and essential oils. Artificial agarwood can reduce the cost of agarwood application [2].

Furthermore, the difference in quality between artificial agarwood and natural agarwood brings certain risks to the application [3]. To date, there have been no reports on the application of artificial agarwood, no scientific evaluation of the effect of the application of artificial agarwood, and no accurate assessment of application risks [4]. Studying these is critical for the large-scale scientific application of artificial agarwood. Agarwood exists in different forms, as shown in Fig. 2.

This study focuses on the environmental impact of agarwood and the impact of particulate matter caused by the burning or smoking of agarwood. This is the

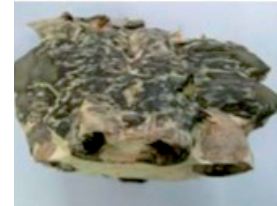

a)

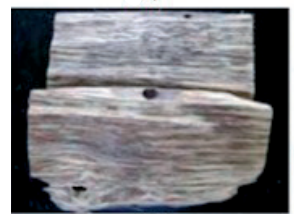

d)

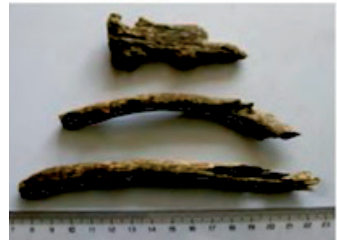

q)

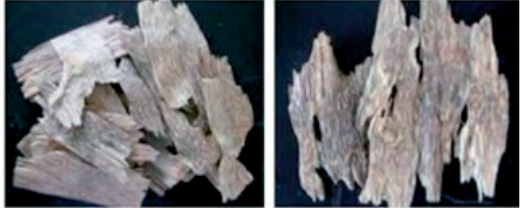

b)

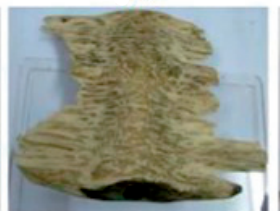

e)

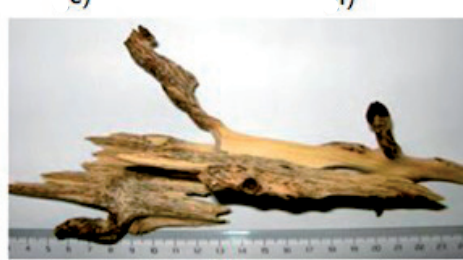

h)
Fig. 2. Different forms of Agarwood for extraction purposes.

first systematic study of the effect of artificial agarwood used in cigarettes [5]. Research results show that the addition of artificial agarwood is beneficial to improve the smoking experience of cigarettes and reduce the irritation of mainstream smoke in a certain range of addition [6]. This research is beneficial to expand the application of artificial agarwood and provide data support for the reasonable substitution of artificial agarwood for cigarettes.

\section{Environmental Conditions for the Growth of Agarwood}

Agarwood belongs to the plant species of the Aquilaria family. It mostly grows in tropical and subtropical areas, such as southern China, Guangdong,

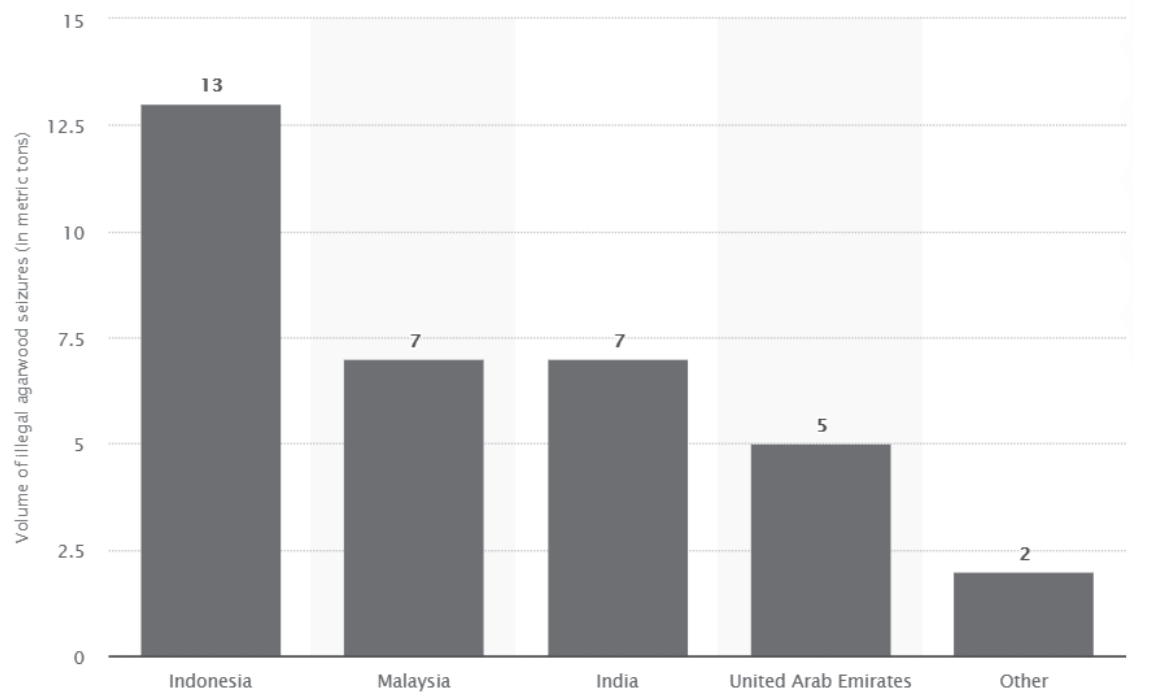

Fig. 1. Volume of illegal agarwood trade seizures worldwide by source country from 2005 to 2014 (in metric tons). 
Vietnam, and Indonesia. The growing environment of agarwood is very high in soil and humidity. There is only a small probability that agarwood trees will produce incense, and therefore it is necessary to determine the conditions that will make agarwood trees produce incense [7, 8]. Many environmental conditions are required to produce good agarwood with respect to the surroundings [9-11].

\section{Soil Impact}

Generally, the soil in which agarwood trees grow is acidic, and the soil requirements are not very high. In acidic soil, sandy loam, yellow loam, and red loam are suitable for the growth of agarwood [12]. However, the soil moisture varies in different production areas. The soil near the production area in Vietnam is relatively dry, whereas the soil near the production area in Indonesia is moist [13]. Moreover, the agarwood formed from different soils is different. The agarwood from the dry soil is sweet and the soil is moist.

\section{Fragrance-Bearing Environment}

The environment where agarwood grows is mostly 100 600 meters above sea level. The higher the altitude, the more intense and purer the fragrance of agarwood. The more famous place is the Jianfengling area in Hainan, China. The quality of agarwood from this production area is special. With sufficient moisture and a suitable temperature, the aroma of agarwood is particularly pure. This environment makes the quality of the resulting incense particularly high $[14,15]$.

\section{Suitable Temperature Environment}

Agarwood trees grow best in a high-temperature environment. The highest temperature is 37 degrees, the lowest temperature is 3 degrees, and the average temperature is around 20 degrees. Even in winter, the short-term low-temperature environment will not affect its growth. Relatively, the higher the temperature, the faster agarwood will grow [16]. Due to the temperature difference, the agarwood produced is different. The agarwood from a place with a high temperature is fresher, whereas the agarwood from a place with a lower temperature is more intense [17].

\section{Tree Age}

It takes between 10 and 20 years for agarwood trees to grow from seedlings to adulthood, and it takes at least 10 years to form incense after being subjected to external forces. Therefore, it takes decades or even hundreds of years to form good-quality agarwood. The longer this period is, the richer the oil of agarwood is, and the density of the oil will increase relatively. At this time, the possibility of agarwood is great, and the appearance is better. The aroma and oil are top-notch [18].

Agarwood forming incense is a miraculous natural phenomenon. The environment in which it forms incense is highly complicated [19, 20]. Only one in thousands of agarwood trees can produce good agarwood, and it takes more than 20 years for agarwood to become incense-bearing. Furthermore, it takes hundreds or thousands of years, and some healthy growth for decades or hundreds of years may not be able to form agarwood. It is for this reason that agarwood is said to be like gold since the formation of agarwood is a very rare thing, so agarwood has always been favored by people since ancient times.

Burning agarwood can produce a pleasant fragrance. The application range of agarwood burning incense is very wide, from people's daily life to some religious activities. Usually, irregular agarwood pieces a few centimeters long and weighing 10-200 g can be cut into smaller pieces of agarwood and burned in a special incense burner. Agarwood powder can be made into agarwood incense and coiled incense. It can be used as daily incense or for religious activities, and it can also be used as an incense [21]. In Taiwan, a province of China, consumers buy agarwood to make incense sticks, which are used to pray for good luck and safety in traditional festivals [22]. Agarwood is also an indispensable component of incense in mainland China and India. In India, high-end agarwood may even contain agarwood essential oil. Agarbattis, the leading brand in the Indian incense market, originally contained a small amount of agarwood powder. However, as the price of agarwood is continually increasing, it is now mostly replaced by waste left over from extracting essential oils, which cost about US\$5/kg. In the Japanese market, there are different grades of fragrances. The top fragrances are made from natural agarwood and contain agarwood powder extract and other spices such as sandalwood and benzoin, which are then carefully baked and shaped; Japanese market It also contains pure fragrance made from agarwood. In Malaysia, Muslims light small pieces of agarwood during special religious gatherings to create smoke [23]. According to records, agarwood is also used during Ramadan prayers. In addition, agarwood sticks are used for bathroom air purification, and in some households, incense is burned continually.

Agarwood has been the best in incense since its independence and has great medicinal value. These two characteristics have led to agarwood being in short supply. Good agarwood is worth US\$1,000. Driven by this interest, natural agarwood in various agarwoodproducing areas resources have been developed by carpet search, resulting in the fact that natural agarwood resources were almost exhausted by the 1990s. Under this background, various artificially induced agarwood trees to quickly produce incense technology came into being. This agarwood is about to enter the market. Due to the high barriers to entry for medicinal materials, the application prospects of this batch of artificial agarwood 
in the medicinal material market will certainly be concentrated in non-medicinal fields. The gap may also bring certain unknown risks to the application, and the supply of a large amount of artificial agarwood needs to develop new applications to digest the supply [24]. Therefore, it is necessary to systematically evaluate the effect of the application of artificial agarwood and natural agarwood in non-medicinal fields, especially to evaluate the safety of their application, which is necessary for the development of the artificial agarwood application market and scientific and reasonable application.

Furthermore, in some parts of China, a small number of smokers insert thin agarwood sticks into cigarettes. These smokers believe that this method of consumption can reduce the irritation caused by cigarettes in the throat and reduce the negative health effects of cigarettes in China, which is the world's largest tobacco consumer. The number of smokers has exceeded 350 million, accounting for one-third of the world's smokers [25]. In China, a large number of cigarettes are consumed every year. Gaining an understanding of the effect of artificial agarwood in cigarettes and the safety of its application will greatly expand the application market of artificial agarwood and have a warning effect on the behavior of a small number of smokers who insert agarwood into cigarettes [26].

The main research content of this article includes the aspects outlined below.

The first aim of the research was to conduct an indepth study of the difference in quality between artificial agarwood and natural agarwood and establish a method to analyze the volatile components of burning agarwood particles. The particulate matter in the burning aerosol was captured, the extraction effect of different solvents was studied, and the solvent extraction parameters were optimized.

The second aim was to scientifically evaluate the health risks of artificial agarwood used in incense and cigarettes, and an in vitro method for evaluating the genotoxicity and cytotoxicity of burning particulate matter was established. The effect, cytotoxicity and genotoxicity of artificial agarwood used in burning incense were studied. The particle distribution of the burning aerosol was measured to assess the possibility of particles entering the alveoli, the concurrence components of the particulate matter were analyzed and compared with those of natural agarwood to assess the quality of the aroma, and the toxicity and genotoxicity of cells of the particulate matter toxicity were tested in vitro and compared with those of natural agarwood.

The third aim was to improve the extraction efficiency of agarwood essential oil, minimize the consumption of agarwood, and study the application value of artificial agarwood essential oil. The supercritical $\mathrm{CO}_{2}$ method, a new type of essential oil extraction technology, was used to extract agarwood essential oil, and various extraction parameters were optimized. The components of the extracted agarwood essential oil were analyzed and compared with those of natural agarwood essential oil, and the antibacterial activity of artificial agarwood was tested.

\section{Materials and Methods}

This study used a self-designed and self-built smoke collection device to collect the particulate matter after burning agarwood, extract it, and optimize the extraction solvent and extraction conditions. In addition, it applied a detection method to analyze the volatile components in agarwood essential oil.

To qualitatively assess and quantify the volatile components in the burning particulate phase of agarwood, it is necessary to collect a comprehensive sample of the burning particulate matter of agarwood. To avoid changes in the combustion state caused by changes in the temperature and humidity of the combustion environment, the entire collection test was carried out in a room with constant temperature and humidity [27]. The temperature was controlled at $22 \pm 2{ }^{\circ} \mathrm{C}$, and the humidity was controlled at $60 \pm 5 \%$. The same agarwood was placed in a box with constant temperature and humidity $\left(22 \pm 1^{\circ} \mathrm{C}, 60 \pm 2 \%\right.$, respectively) for 48 hours before burning.

Based on the library search, the processed sample in the chromatographic bottle was qualitatively and quantitatively detected by a gas-mass spectrometer, quantified based on the total ion current peak area, and quantified by the phenethyl acetate internal standard method.

The gas chromatographic conditions were as follows: the column was DB-5MS (Agilent, $60 \mathrm{~m} \times$ $0.25 \mathrm{~mm}$ id $\times 0.25 \mu \mathrm{m}$ ); the carrier gas was helium, and the flow rate was $1.0 \mathrm{~mL} /$ minute; the split ratio was $30: 1$; the injection volume was $1 \mu \mathrm{L}$; the temperature of the injection port was $280^{\circ} \mathrm{C}$; and the temperature program was the initial temperature was $40^{\circ} \mathrm{C}$, and then it was increased to $280^{\circ} \mathrm{C}$ at a rate of $1.5^{\circ} \mathrm{C} /$ minute and maintained for 20 minutes. The mass spectrometry conditions were as follows: the transmission line temperature was $280^{\circ} \mathrm{C}$; the ion source temperature was $230^{\circ} \mathrm{C}$; the quadrupole temperature was $150^{\circ} \mathrm{C}$; the electron impact (EI) ionization voltage was $70 \mathrm{eV}$; the mass number range was 50 550 amu; and the MS library was Wiley $05+$ Nist 08 series search.

\section{Results and Discussion}

This study as compared to other studies is only focused on smoke particles emitted after burning of agarwood while other studies focuses on combination of molecular impact of agarwood. Qualitative analysis of the spectrum library of the gas-mass spectrometry spectrum of agarwood burning smoke particlephase components was carried out, and then semi- 
Table 1 . The similarity of volatile components of particulate matter in four samples of agarwood incense $(\mu \mathrm{g} / \mathrm{g})$.

\begin{tabular}{|c|c|c|c|c|c|}
\hline $\begin{array}{c}\text { Serial } \\
\text { number }\end{array}$ & Name & Agarwood 1 & Agarwood 2 & Agarwood 3 & Agarwood 4 \\
\hline 1 & 2-Methoxy-4-vinylphenol & $1217.53 \pm 45.04$ & $3200.64 \pm 57.45$ & $2474.89 \pm 76.90$ & $937.29 \pm 58.27$ \\
\hline 2 & 2,6-dimethoxy-Phenol & $4417.08 \pm 46.54$ & $7091.98 \pm 141.52$ & $5264.64 \pm 489.19$ & $3956.10 \pm 372.87$ \\
\hline 3 & Eugenol & $191.29 \pm 0.43$ & $403.52 \pm 24.24$ & $290.69 \pm 13.99$ & $443.38 \pm 19.63$ \\
\hline 4 & Vanillin & $2386.03 \pm 50.49$ & $2093.55 \pm 46.36$ & $1353.14 \pm 34.11$ & $1825.05 \pm 145.64$ \\
\hline 5 & trans-Isoeugenol & $1320.42 \pm 17.25$ & $2035.80 \pm 29.73$ & $1584.85 \pm 40.75$ & $750.87 \pm 47.65$ \\
\hline 6 & 2-methoxy-4-propyl-Phenol & $176.36 \pm 14.84$ & $70.89 \pm 3.70$ & $43.07 \pm 0.26$ & $477.54 \pm 40.84$ \\
\hline 7 & Apocynin & $1078.97 \pm 37.15$ & $1874.75 \pm 90.96$ & $473.07 \pm 6.26$ & $576.79 \pm 59.28$ \\
\hline 8 & 4-hydroxy-3,5-dimethoxy-Benzaldehyde & $4593.63 \pm 99.46$ & $2794.85 \pm 77.17$ & $2786.10 \pm 52.08$ & $5441.33 \pm 37.79$ \\
\hline 9 & 2,6-dimethoxy-4-(2-propenyl)-Phenol & $1121.52 \pm 17.49$ & $1189.73 \pm 23.68$ & $1046.96 \pm 16.68$ & $1217.07 \pm 40.16$ \\
\hline 10 & 2,6-dimethoxy-4-(2-propenyl)-Phenol & $730.59 \pm 21.64$ & $467.47 \pm 8.67$ & $346.94 \pm 3.34$ & $514.92 \pm 46.76$ \\
\hline 11 & $\begin{array}{l}\text { trans-2,6-dimethoxy-4-(1-propenyl)- } \\
\text { Phenol }\end{array}$ & $3905.87 \pm 94.37$ & $2892.52 \pm 56.82$ & $2666.75 \pm 155.08$ & $4661.07 \pm 346.05$ \\
\hline \multicolumn{6}{|c|}{ Methoxy-containing phenols and derivatives } \\
\hline 1 & Phenol & $79.89 \pm 0.97$ & $1215.42 \pm 23.18$ & $484.07 \pm 26.66$ & $52.10 \pm 5.00$ \\
\hline 2 & Phenol, 2-methoxy- & $618.52 \pm 30.04$ & $3000.44 \pm 101.86$ & $934.95 \pm$ & $319.35 \pm 1.47$ \\
\hline 3 & 3-Methoxy-5-methylphenol & $101.37 \pm 4.14$ & $196.26 \pm 9.60$ & $60.22 \pm$ & $46.00 \pm 3.11$ \\
\hline 4 & Sinapinaldehyde & $2943.91 \pm 100.22$ & $430.95 \pm 33.47$ & 1513.18 & $4493.53 \pm 123.19$ \\
\hline 5 & 1,2,4-Trimethoxybenzene & $2119.90 \pm 47.96$ & $2784.71 \pm 35.11$ & 2109.69 & $1899.69 \pm 143.34$ \\
\hline 6 & 6-Methoxy-3-methylbenzofuran & $163.73 \pm 6.53$ & $123.36 \pm 2.60$ & $44.33 \pm$ & $115.08 \pm 3.01$ \\
\hline 7 & 3,5-Dimethoxyacetophenone & $3796.78 \pm 22.85$ & $3547.15 \pm 185.39$ & 3570.92 & $3685.26 \pm 59.85$ \\
\hline & & sar degradation pr & lucts & & \\
\hline 1 & Furfural & $21.42 \pm 1.19$ & $36.14 \pm 1.91$ & 151.07 & $77.30 \pm 2.60$ \\
\hline 2 & 2-Furanmethanol & $74.61 \pm 3.41$ & $31.05 \pm 0.75$ & $185.82 \pm$ & $72.79 \pm 5.00$ \\
\hline 3 & 2(5H)-Furanone & $143.31 \pm 6.10$ & $171.43 \pm 6.57$ & $265.59 \pm$ & $189.94 \pm 5.74$ \\
\hline 4 & $\begin{array}{l}\text { 1,4:3,6-Dianhydro- } \alpha \\
\text {-d-glucopyranose }\end{array}$ & $744.10 \pm 27.70$ & $642.01 \pm 22.64$ & $683.53 \pm$ & $582.15 \pm 53.32$ \\
\hline 5 & 2,3-Anhydro-d-mannosan & $347.08 \pm 7.02$ & $306.20 \pm 3.97$ & $331.92 \pm$ & $357.00 \pm 24.61$ \\
\hline 6 & 5-Hydroxymethylfurfural & $1651.90 \pm 64.08$ & $458.48 \pm 3.89$ & 1099.29 & $1588.53 \pm 136.48$ \\
\hline & & Others & & & \\
\hline 1 & 3-Methyl-1,2-cyclopentanedione & $51.73 \pm 0.49$ & $96.69 \pm 9.30$ & $151.87 \pm$ & $62.34 \pm 4.16$ \\
\hline 2 & Benzylacetone & $78.38 \pm 4.71$ & $862.89 \pm 12.07$ & $3959.80 \pm$ & $187.01 \pm 16.82$ \\
\hline & Total & 34075.91 & 38018.89 & $3387^{\prime}$ & 34529.51 \\
\hline 1 & 4-Methyl-5H-furan-2-one & $35.51 \pm 1.33$ & 61.5 & \pm 6.09 & $74.67 \pm 1.29$ \\
\hline 2 & Maltol & $311.26 \pm 4.23$ & 192.5 & \pm 18.52 & $296.71 \pm 4.72$ \\
\hline 3 & Creosol & $1851.97 \pm 160.8$ & 1510.9 & \pm 32.30 & $620.84 \pm 41.54$ \\
\hline 4 & Desaspidinol & $969.43 \pm 31.83$ & 1103.0 & \pm 46.10 & $912.65 \pm 3.02$ \\
\hline & Total & 3168.17 & & 3.06 & 1904.86 \\
\hline
\end{tabular}


quantitative analysis was carried out with the internal standard of phenethyl acetate. A total of 66 substances were identified. The identified substances are mainly small molecular volatiles and three sugar degradation products, nine monoterpenoids, and eight methoxycontaining phenolic compounds. Monoterpenoids mainly exist in the secretory tissues of higher plants, and methoxyphenyl compounds are mainly produced by the degradation of lignin. Unlike the studies in the literature which reported that the composition of the essential oil of agarwood is mainly sesquiterpenoids, sesquiterpenoids were rarely detected in the volatile components in the smoke phase of agarwood burning. Based on the literature search and analysis of the aroma characteristics of the volatile components of the smoke particles of agarwood listed in Table 1, a total of 23 substances with various aroma characteristics that are commonly used in the preparation of food flavors were identified. The aroma characteristics are shown in the last column of the table. These substances make a great contribution to the pleasant taste of agarwood after burning. They account for more than $45 \%$ of the total mass of the identified substances. Most of the chromatographic peaks in the spectrum after 120 minutes have been compared and identified in the literature, and most of them are chromones.

Agarwood burning smoke particles and chemical components in agarwood essential oil:

Gas-mass spectrometry analysis was performed on the components of agarwood burning smoke particles and agarwood essential oil. The spectra are shown in Fig. 3 and Fig. 4, respectively. The main components of agarwood burning smoke particles are concentrated before the peak at 90 minutes, while the main components of the agarwood essential oil are concentrated at the peak after 80 minutes. It can

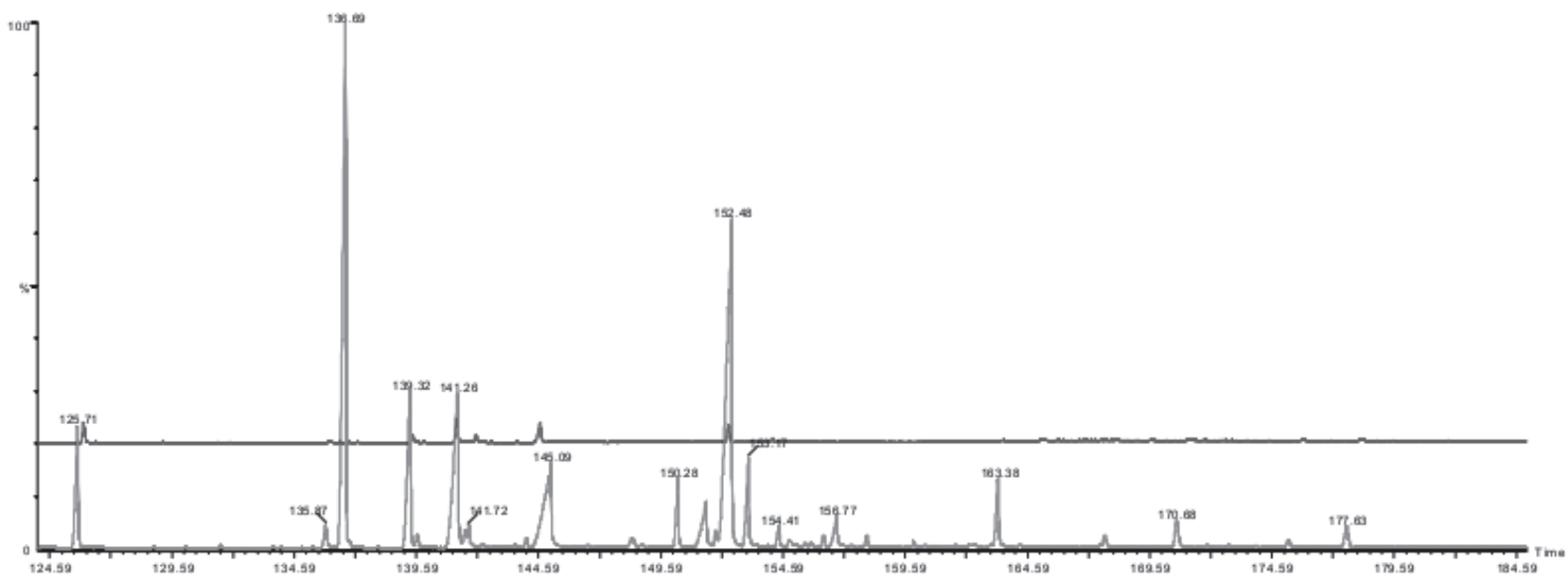

Fig. 3. Gas chromatography/mass spectrometry spectrum of combustion particulate matter of agarwood.

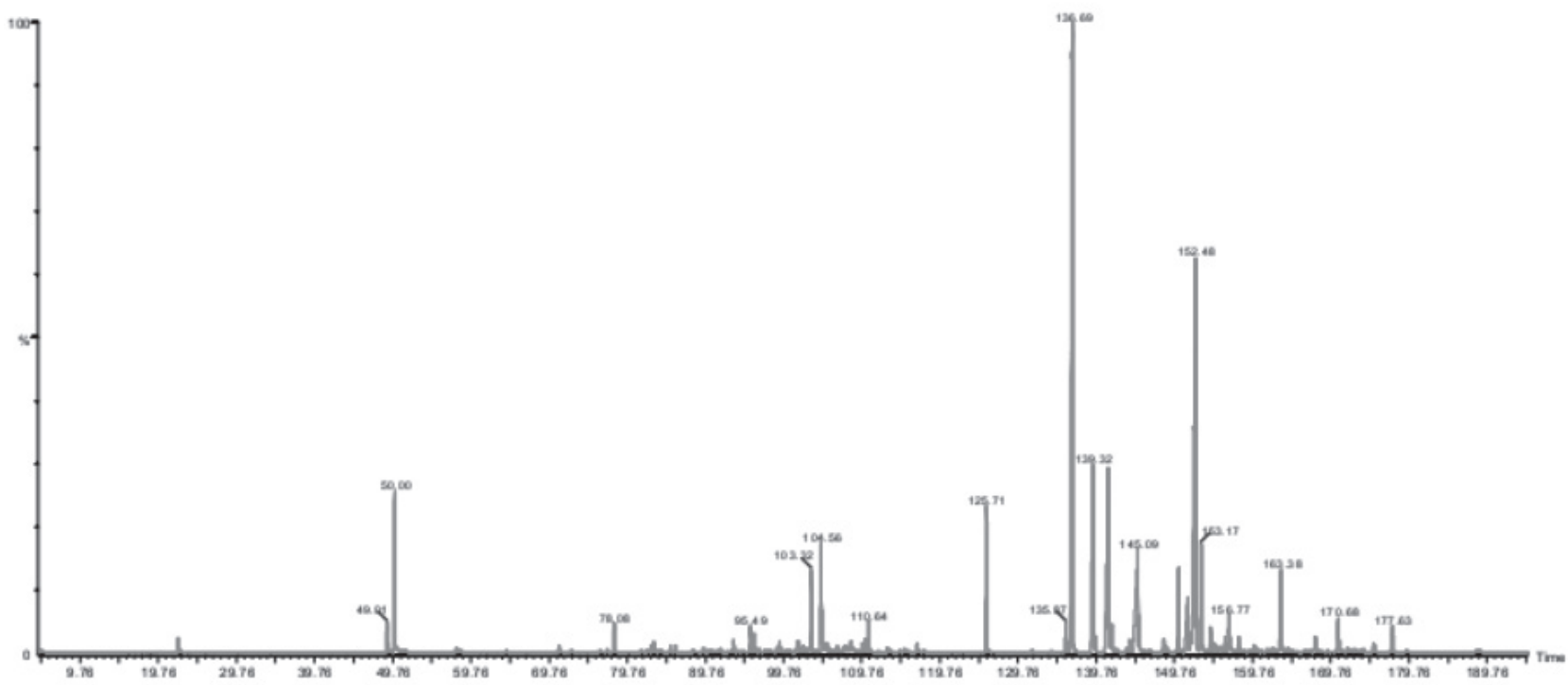

Fig. 4. Gas chromatography-mass spectrometry chromatograms of agarwood essential oil. 
be seen that the agarwood burning smoke particles are mainly small molecular substances with low boiling points, whereas there are more large molecular substances with high boiling points in essential oils.
For details, see Fig. 5. Fig. 5a) is a comparison of the two chromatograms before 75 minutes. It can be seen that there are many small-area peaks in the phase spectra of agarwood burning smoke particles in this

a)

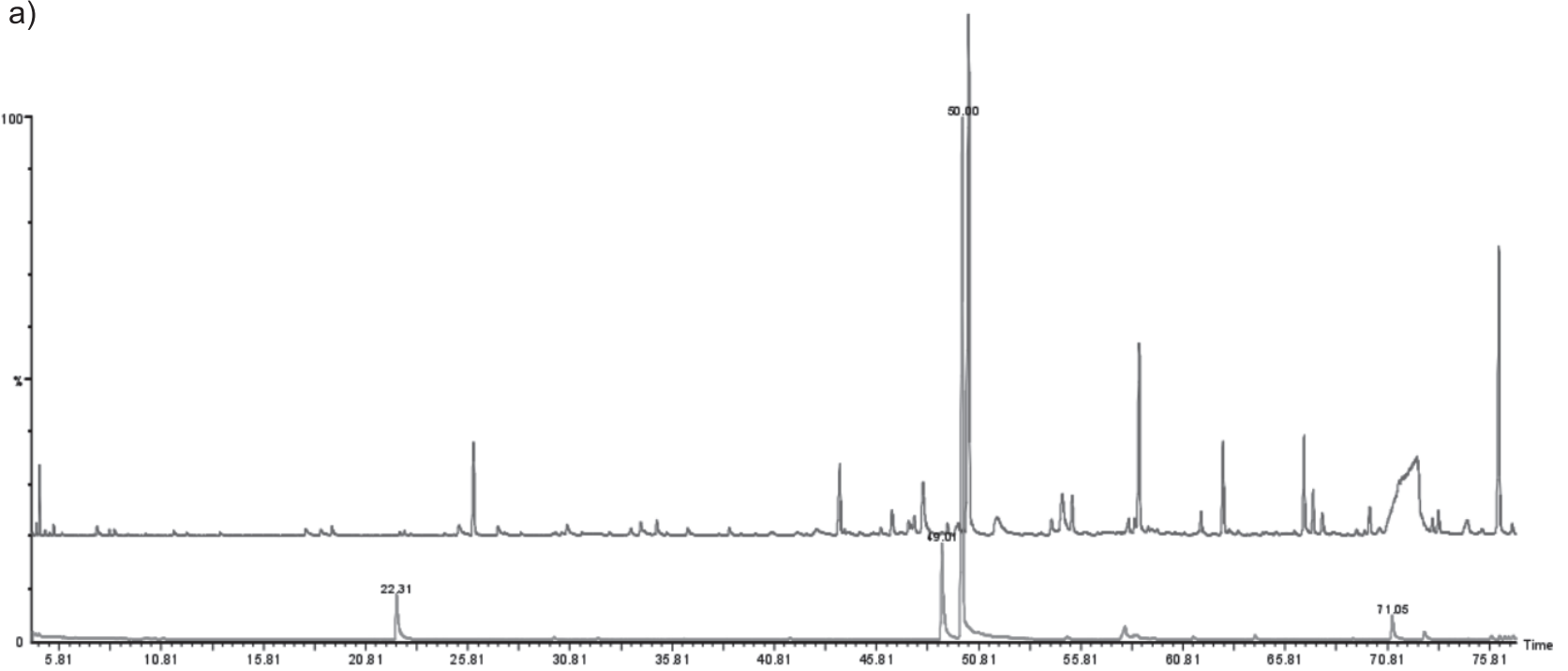

b)
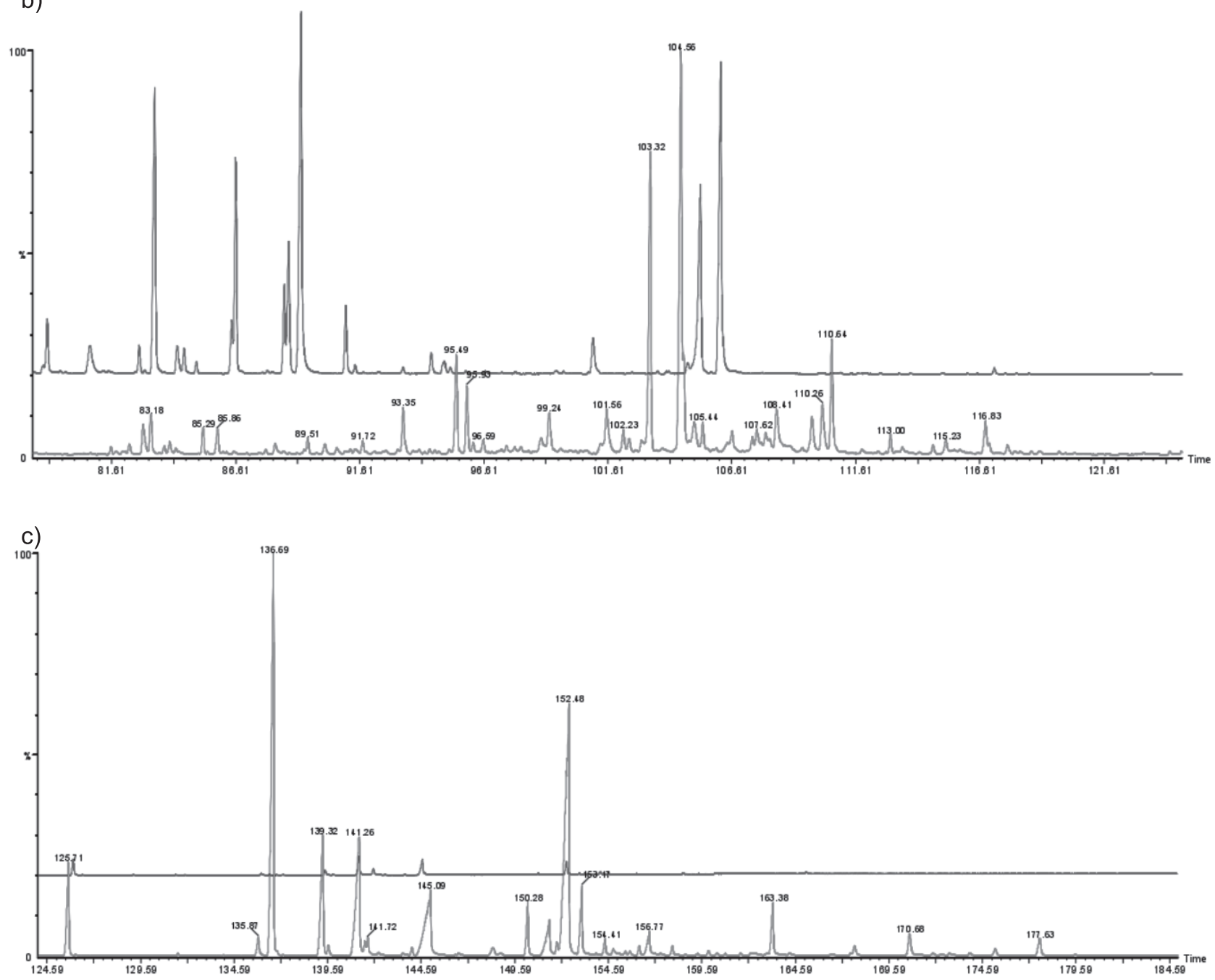

Fig. 5. Agarwood essential oil and the extracts of the particles emitted when agarwood incense was burned. 
section, while the agarwood essential oil sample is in this section of the baseline. It is very flat, with only a few peaks. According to the spectrum library identification, the peaks of agarwood burning smoke in this section are all compounds with less than ten carbon chain molecules, mainly small molecular volatile substances, containing some monoterpenes and degraded sugars (see Table 1). Fig. 5b) is a comparison of the two chromatograms between 75 minutes and 120 minutes. Agarwood essential oil samples have more peaks in this section, while agarwood burning smoke particulate matter samples are relatively high in this section. There are few peaks, but the peak area is larger. According to the identification of the spectrum library, the peaks of the agarwood essential oil sample are mainly sesquiterpenoids, which are closely related to the unique aroma characteristics of agarwood. The peaks of agarwood burning smoke in this section are mainly phenolic substances containing methoxy groups. Fig. 5c) is a comparison of the two chromatograms after 120 minutes. It can be seen that the sample of agarwood burning smoke does not peak after 120 minutes. A large number of substances in the agarwood essential oil sample peaked after 120 minutes, and the literature and library identified mostly chromones, sterols, long-chain fatty acids, and fatty acid esters.

\section{Conclusions}

There are some differences in the quality of artificial agarwood and natural agarwood due to its short setting time. Its application in formulating traditional Chinese medicine is subject to certain restrictions. This is the first systematic study of the differences in volatile substances, aerosol particle status, cytotoxicity, and genotoxicity between artificial agarwood burning smoke and natural agarwood burning smoke. Agarwood burning smoke is harmful to health, and artificial agarwood burning smoke causes toxic harm. Findings of this study can help in reversing the long-standing misconceptions that incense is good for purifying the air, refreshing, and good for human health by guiding people to correctly understand the effect of incense, and scientifically and rationally applying artificial incense agarwood to burning incense.

Future work will be focused on finding the ways to reduce air pollution and focusing on indoor as well as outdoor air pollution methods for improving the quality of air.

\section{Acknowledgments}

This work was financially supported by the National Natural Science Foundation of China [41625004, 41971404] and the National Key R\&D Program of China [2017YFB0503500].

\section{Conflict of Interest}

The authors declare no conflict of interest.

\section{References}

1. BHATTI U.A., YAN Y., ZHOU M., ALI S., HUSSAIN A., QINGSONG H., YUAN L. Time Series Analysis and Forecasting of Air Pollution Particulate Matter (PM 2.5): An SARIMA and Factor Analysis Approach. IEEE Access, 9, 41019, 2021.

2. OPPERMAN J.J., BERNAZZI P., BURFIELD T., JOHNSON K., MASON R. Endangered species update, 20, 3 (May/June 2003) 2003.

3. PRETORIUS ISAK S. "Synthetic genome engineering forging new frontiers for wine yeast." Critical reviews in biotechnology 37.1, 112, 2017.

4. ROE D. Trading nature. A Report, with Case Studies, on the Contribution of Wildlife Trade Management to Sustainable Livelihoods and the Millennium Development Goals. TRAFFIC International and WWF International, Cambridge, UK. 2008.

5. SCHULZE F., GAO X., VIRZONIS D., DAMIATI S., SCHNEIDER M.R., KODZIUS R. Air quality effects on human health and approaches for its assessment through microfluidic chips. Genes, 8 (10), 244, 2017.

6. MOERAN B. The business of creativity: Toward an anthropology of worth 1. Left Coast Press. 2013.

7. BARDEN A., ANAK N.A., MULLIKEN T., SONG M. Heart of the matter: agarwood use and trade and CITES implementation for Aquilaria malaccensis. Traffic International, Cambridge, UK. 2000.

8. RASOOL S., MOHAMED R. Understanding agarwood formation and its challenges. In Agarwood (pp. 39-56). Springer, Singapore. 2016.

9. AZREN P.D., LEE S.Y., EMANG D., MOHAMED R. History and perspectives of induction technology for agarwood production from cultivated Aquilaria in Asia: a review. Journal of Forestry Research, 30 (1), 1, 2019.

10. LÓPEZ-SAMPSON A., PAGE T. History of use and trade of agarwood. Economic botany, 72 (1), 107, 2018.

11. BHATTI U.A., YUAN L., YU Z., NAWAZ S.A., MEHMOOD A., BHATTI M.A., XIAO S. Predictive Data Modeling Using sp-kNN for Risk Factor Evaluation in Urban Demographical Healthcare Data. Journal of Medical Imaging and Health Informatics, 11 (1), 7, 2021.

12. CHOWDHURY M.I.L.O.N. Production of agarwood through aeration method into the agar tree. Unpublished master's thesis). Bangladesh Agricultural University, Mymensingh. 2014.

13. VAN DER HOUT P. Resource Assessment and Forest Management Plan for the CITES-Listed Species Cedrela odorata (red cedar) In Guyana. 2015.

14. BHATTI U.A., HUANG M., WU D., ZHANG Y., MEHMOOD A., HAN H. Recommendation system using feature extraction and pattern recognition in clinical care systems. Enterprise information systems, 13 (3), 329, 2019.

15. SKARIA B.P. Aromatic plants (Vol. 1). New India Publishing. 2007.

16. YIQIN Z. Effets des températures fraîches $\left(5^{\circ} \mathrm{C}-25^{\circ} \mathrm{C}\right)$ sur la fermentation et l'entreposage d'ensilages de maïs plante entière (Doctoral dissertation, Université du Québec en Abitibi-Témiscamingue). 2014. 
17. BEELDERS T. Xanthones and benzophenones from Cyclopia genistoides (honeybush): chemical characterisation and assessment of thermal stability (Doctoral dissertation, Stellenbosch: Stellenbosch University). 2016.

18. TURIN L., SANCHEZ T. Perfumes: The AZ Guide. Profile Books. 2010.

19. ARTHUR S. Wafting incense and heavenly foods: the importance of smell in Chinese religion. Body and Religion, 2 (2), 144, 2018.

20. GOLLNER A. The book of immortality: the science, belief, and magic behind living forever. Simon and Schuster. 2013.

21. LE T. Scentscapes: Understandings of Nature, Consumption, and Commodification through Agarwood and Olfaction (Doctoral dissertation, UCLA). 2018.

22. BARDEN A., ANAK N.A., MULLIKEN T., SONG M. Heart of the matter: agarwood use and trade and CITES implementation for Aquilaria malaccensis. Traffic International, Cambridge, UK. 2000.

23. AKTER N., NEELIM A.Z. Agarwood plantation at BRAC Tea Estate: introduction, environmental factors and financial analysis. 2008.
24. DAVIDSON G., CHUA T.H., COOK A., SPELDEWINDE P., WEINSTEIN P. The role of ecological linkage mechanisms in Plasmodium knowlesi transmission and spread. EcoHealth, 1, 2019.

25. NIZAMANI M.M., BHATTI U.A., CHENG X.L., NIZAMANI F.G., RIND R.A., KHOKHAR A.A., YANG D.M. The Connections between Above-Ground Biomass and Plant Diversity of Roadside Trees, Density and Diversity on Different Types of Roads in Karachi. Polish Journal of Environmental Studies. 2021

26. EKDAHL K.N., FROMELL K., MOHLIN C., TERAMURA Y., NILSSON B. A human whole-blood model to study the activation of innate immunity system triggered by nanoparticles as a demonstrator for toxicity. Science and technology of advanced materials, 20 (1), 688, 2019.

27. SCHULZE F., GAO X., VIRZONIS D., DAMIATI S., SCHNEIDER M.R., KODZIUS R. Air quality effects on human health and approaches for its assessment through microfluidic chips. Genes, 8 (10), 244, 2017. 
